\title{
Perancangan dan Analisis Body Wahana UAV 3 Medan AMPHI-FLY Evo 1.0
}

\author{
Agung Dwi Sapto*, Rivan Dia Eka \\ Jurusan Teknik Mesin, Fakultas Teknologi Industri, Universitas Gunadarma \\ Jl. Margonda Raya 100, Depok, Jawa Barat \\ *E-mail: adwisapto98@gmail.com
}

Diterima: 08-07-2021; Direvisi: 06-08-2021; Dipublikasi: 27-08-2021

\begin{abstract}
Abstrak
Kendaraan Tanpa Awak (Unmanned Aerial Vehicle) dalam bidang kemanusiaan sudah banyak digunakan, khususnya dalam misi pencarian dan penyelamatan. Tujuan penelitian ini adalah untuk menghasilkan prototipe kendaraan tanpa awak (UAV) yang berfungsi untuk membantu proses pencarian dan penyelamatan pada 3 medan (udara, darat, permukaan air). UAV AMPHI-FLY Evo 1.0 merupakan sebuah teknologi yang dirancang dan dikembangkan untuk memaksimalkan fungsi UAV, yang selama ini hanya memiliki fungsi terbatas pada 1 atau 2 medan dalam pengoperasiannya. Sehingga UAV AMPHI-FLY Evo 1.0 dapat beroperasi di 3 medan sekaligus, yaitu di udara, di darat, dan di permukaan air. Pengembangan teknologi pada UAV AMPHI-FLY Evo 1.0 merupakan solusi agar misi pencarian dan penyelamatan dengan menggunakan UAV lebih optimal dan dapat menjakau berbagai jenis medan yang sulit dan tidak memungkinkan untuk dijangkau manusia. Perancangan dilakukan untuk menentukan spesifikasi komponen wahana UAV AMPHI-FLY Evo 1.0. dilakukan dengan menggunakan software solidworks 2018. Komponen-komponen pada wahana UAV AMPHI-FLY Evo 1.0 secara umum di bagi menjadi 4 kelompok yaitu komponen body utama, komponen penggerak, komponen kelistrikan, komponen tambahan. Komponen wahana yang dirancang adalah Frame, body, lambung kapal (hull), motor penggerak, propeller, rudder, dan estimasi konsumsi baterai. Estimasi berat total wahana yang direncanakan adalah 2807 gr. Frame berfungsi untuk menahan berat wahana dan menunjang performa wahana dalam beroperasi, ukuran Frame yang dipilih adalah 560mm. Body pada wahana memiliki bentuk yang aerodinamis, memiliki nilai $\mathrm{Cd}=0,0198562$. Sedangkan daya hambatan pada $\operatorname{body}\left(P_{d}\right)$ didapatkan sebesar 2,4058 watt.
\end{abstract}

Kata kunci: aerodinamis; perancangan; UAV;

\begin{abstract}
Unmanned Aerial Vehicles in the field of humanity are already widely used, especially in search and rescue missions. The purpose of this research is to produce a prototype unmanned vehicle (UAV) that serves to assist the search and rescue process on 3 terrains (air, land, water level). UAV AMPHI-FLY Evo 1.0 is a technology designed and developed to maximize the function of UAVs, which so far have only limited functions to 1 or 2 terrains in operation. The AMPHI-FLY Evo 1.0 UAV can operate in 3 terrains at once, namely in the air, on land, and on the surface of the water. Technology development in AMPHI-FLY Evo 1.0 UAV is a solution to make search and rescue missions using UAVs more optimal and can reach various types of terrain that are difficult and not possible for humans to reach. The design was carried out to determine the component specifications of amphi-fly evo 1.0 UAV vehicles carried out using solidworks 2018 software. The components in AMPHI-FLY Evo 1.0 UAV vehicles are generally divided into 4 groups, namely the main body components, drive components, electrical components, a supplementation components. The components of the vehicle are frame, body, hull, drive motor, propeller, rudder, and estimated battery consumption. The estimated total weight of the planned rides is 2807 gr. Frame serves to withstand the weight of the vehicle and support the performance of the vehicle in operation, the size of the selected Frame is 560mm. The body on the ride has an aerodynamic shape, has a value of Cd=0.0198562. While the resistance power in the body $(P d)$ is obtained by 2.4058 watts.
\end{abstract}

Keywords: aerodynamics; design; UAV;

\section{Pendahuluan}

Indonesia, secara geografis merupakan negara kepulauan yang berada diantara pertemuan 4 lempeng tektonik yaitu lempeng Asia, lempeng Australia, lempeng Hindia dan lempeng Fasifik. Sehingga Indonesia menjadi salah satu negara yang rawan terjadi bencana gunung berapi, gempa, dan tsunami. Tercatat sepanjang tahun 2018 telah terjadi 2564 bencana yang mengakibatkan 3349 orang meninggal, dan 1432 orang hilang [1]. Selain itu masih banyak kejadian 
lain seperti hilangnya pendaki gunung di jalur pendakian. Seperti yang terjadi pada pendaki di Gunung Lawu, yang hilang pada tanggal 31 Desember 2018, memakan waktu pencarian hingga 23 hari namun hingga saat ini tidak ditemukan [2]. Dari setiap kejadian ini kami termotivasi untuk membuat sebuah alat yang dapat membantu pencarian korban hilang oleh Tim SAR (Search And Rescue) terutama di daerah yang berbahaya dan sulit untuk dijangkau oleh Tim SAR.

UAV model quadcopter juga dapat digunakan untuk melakukan pemetaan dari udara. Data pendukung yang digunakan adalah berupa perekaman Ground Control Point (GCP) menggunakan GPS RTK dengan metode Stop and Go. Data lainnya seperti pengukuran hasil PTSL digunakan untuk memvalidasi data hasil pemotretan foto udara [3]. Untuk kemampuan di permukaan air pemilihan jenis bentuk hull kapal yang tepat adalah untuk mendapatkan stabilitas tinggi, karena kendaraan tanpa awak ini akan memiliki sistem sensor guna membuat keakuratan sensor lebih terjaga. Selain itu kendaraan tanpa awak ini dapat memiliki kecepatan yang sangat tinggi karena bentuk body kendaraan tanpa awak ini runcing namun bisa membawa beban yang cukup besar [4]. Penggunaan pemantauan daerah bencana dengan kendaraan tanpa awak dipilih karena mampu mencapai daerah bencana yang sulit dijangkau dengan cepat, selain itu dapat mengurangi resiko jika daerah bencana tersebut sangat berbahaya bagi manusia, misalnya asap beracun akibat kebakaran [5].

Penelitian diawali dengan merancang dan membahas pembuatan UGV dengan misi pemantauan daerah bencana Kendaraan Tanpa Awak (Unmanned Aerial Vehicle) dalam bidang kemanusiaan sudah banyak digunakan, khususnya dalam misi pencarian dan penyelamatan. Penggunaan UAV yang sudah ada saat ini dinilai efektif di beberapa kondisi, namun di medan yang sulit dan ekstrim terjadi banyak kendala dan salah satunya keterbatasan pergerakan UAV yang hanya bisa beroperasi di salah satu medan. Sehingga pengembangan teknologi pada UAV AMPHI-FLY Evo 1.0 merupakan solusi agar misi pencarian dan penyelamatan dengan menggunakan UAV lebih optimal dan dapat menjakau berbagai jenis medan yang sulit dan tidak memungkinkan untuk dijangkau manusia. UAV AMPHI-FLY Evo 1.0 merupakan sebuah teknologi yang dirancang dan dikembangkan untuk memaksimalkan fungsi UAV, yang selama ini hanya memiliki fungsi terbatas pada 1 atau 2 medan dalam pengoperasiannya. Sehingga perancang berfikir untuk mengembangkan teknologi UAV yang dapat beroperasi di 3 medan sekaligus, yaitu di udara, di darat, dan di permukaan air agar pergerakan yang dapat dilakukan UAV dalam misi pencarian dan penyelamatan lebih optimal.

\section{Material dan Metodologi}

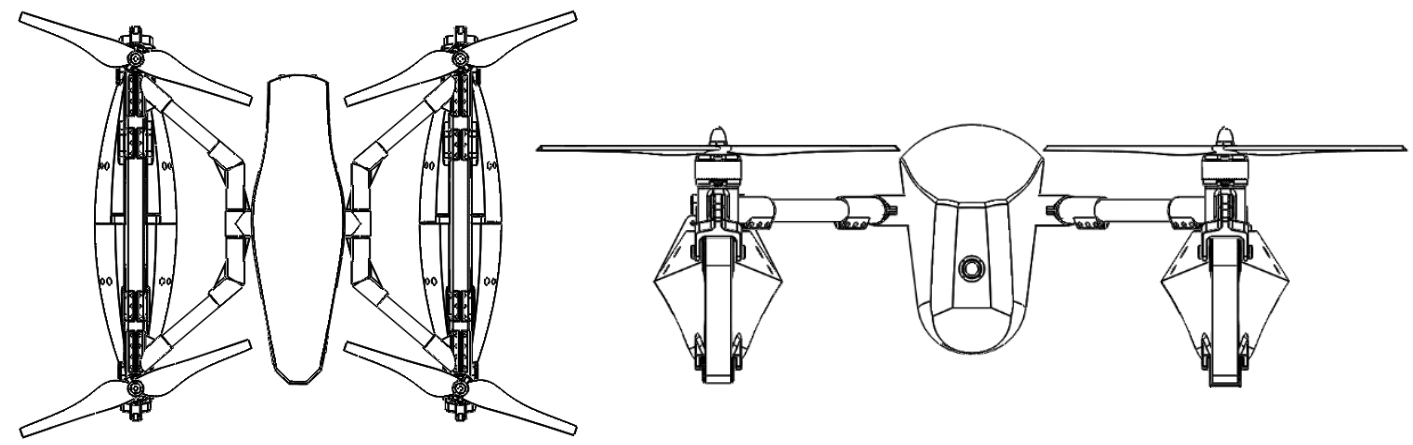

Gambar 1. Model UAV AMPHI-FLY Evo1.0

UAV AMPHI-FLY Evo 1.0 dirancang dan dikembangkan untuk mengoptimalkan fungsi UAV/drone dalam misi pencarian dan penyelamatan. Memiliki keunggulan dapat beroperasi di 3 medan. yaitu di udara, di darat, di permukaan 
air. Selain itu AMPHI-FLY Evo 1.0 dapat dilengkapi dengan kamera resolusi 4K, GPS, dan pemancar gelombang sonar untuk mendukung dalam menjalankan misi. Prinsip kerja AMPHI-FLY Evo 1.0 secara umum adalah bagaimana mengontrol komponen penggerak di masing-masing medan, menerima data, menyimpan data, mentransfer data, dan komponen bentuk fisik secara teknis mendukung agar semua fungsi dapat berjalan dengan baik.

Komponen-komponen pada wahana UAV AMPHI-FLY Evo 1.0 secara umum di bagi menjadi 4 kelompok yaitu komponen body utama, komponen penggerak, komponen kelistrikan, komponen tambahan.

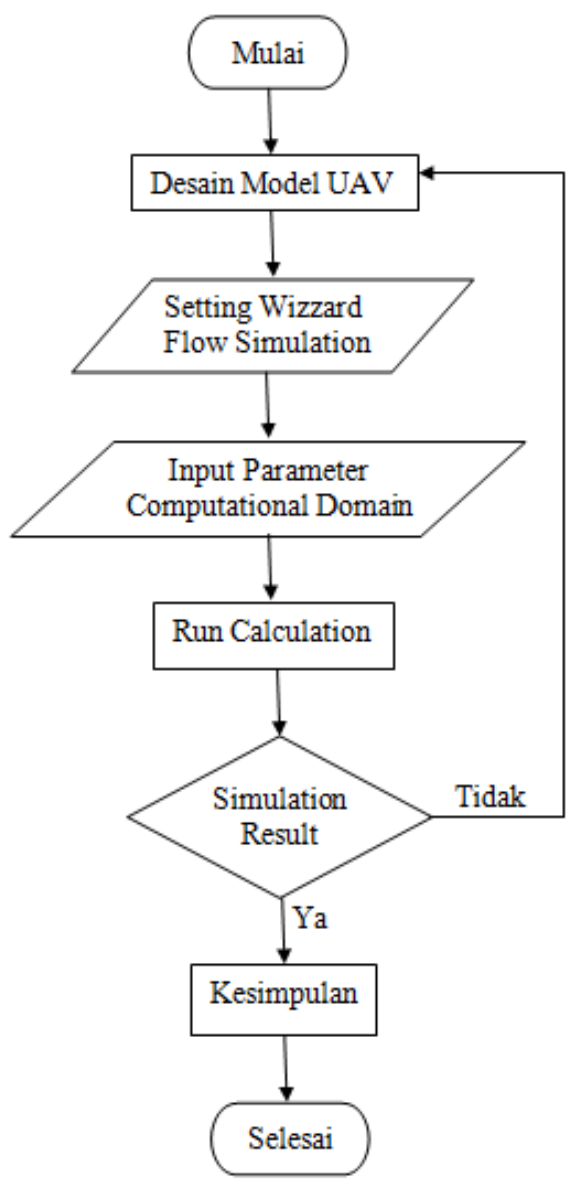

Gambar 2. Diagram Alir Penelitian

\section{Hasil dan Pembahasan}

\subsection{Perancangan Wahana UAV AMPHI-FLY Evo 1.0}

Dalam perancangan wahana UAV AMPHI-FLY Evo 1.0 perhitungan dan analisa dilakukan pada komponen utama yang mempunyai pengaruh besar terhadap kinerja wahana. Untuk memilih spesifikasi motor sebagai komponen penggerak diperlukan torsi, daya, dan rpm yang sesuai terhadap beban dan hambatan pada wahana agar dapat bergerak dengan baik. Untuk perencanaan komponen tubuh utama seperti Frame, body, hull diperlukan ukuran, berat, dan nilai hambatan yang sesuai dengan kebutuhan wahana. Dalam menentukan komponen actuator seperti propeller, rudder, dan roller diperlukan dimensi yang sesuai untuk mendukung kinerja motor sebagai komponen penggerak.

\subsection{Estimasi Berat Wahana}

Untuk mengetahui estimasi berat dari wahana UAV AMPHI-FLY Evo 1.0, dilakukan dengan 2 cara yaitu, yang pertama menggunakan software Solidworks 2018 untuk mengukur berat untuk bagian komponen tubuh utama. Dengan 
Agung Dwi Sapto dkk /Jurnal Rekayasa Mesin

p-ISSN: 1411-6863, e-ISSN: 2540-7678

Vol.16|No.2|148-156|Agustus|2021

membentuk setiap komponen yang diberikan spesifikasi material lalu diukur dengan fungsi mass properties. Yang kedua menimbang dengan timbanga, untuk bagian komponen penggerak, komponen kelistrikan, dan komponen optional. Dengan menimbang secara langsung setiap komponen tersebut. Berikut tabel hasil penimbangan komponen wahana berdasarkan berat perkomponen dikali jumlah komponen, pada wahana UAV AMPHI-FLY Evo 1.0

Tabel 1. Tabel Berat Komponen Wahana AMPHI-FLY Evo 1.0

\begin{tabular}{|c|c|c|c|c|c|}
\hline No. & Detail Komponen & Berat $(g r)$ & No. & Detail Komponen & Berat (gr) \\
\hline 1. & Frame arm & 82 & 18. & Brushed motor (darat) & 230 \\
\hline 2. & Motor mounting & 142 & 19. & Brushed motor (air) & 160 \\
\hline 3. & Hull mounting & 40 & 20. & Water Propeller & 65 \\
\hline 4. & Track tension adjuster & 29 & 21. & Rudder & 36 \\
\hline 5. & Main bracket & 59.5 & 22. & Servo motor & 13 \\
\hline 6. & Y hub & 43 & 23. & Track transmision & 156 \\
\hline 7. & Side Hull & 78 & 24. & Flight controller $(F C)$ & 31 \\
\hline 8. & Roller track & 64 & 25. & ESC & 234 \\
\hline 9. & Stoper hull & 21 & 26. & Radio transmitter & 19 \\
\hline 10. & Upper body & 76 & 27. & GPS module & 16 \\
\hline 11. & Under hull body & 81 & 28. & Radio reciever & 432 \\
\hline 12. & Main base & 41 & 29. & $P D B$ & 20 \\
\hline 13. & Camera bracket & 34 & 30. & Battery Li-Po & 14 \\
\hline 14. & Bracket to base & 31 & 31. & Power checker & 2,5 \\
\hline 15. & Tube & 23 & 32. & FPV Camera & 26 \\
\hline 16. & Brushless motor & 408 & 33. & Video transmitter & 31 \\
\hline 17. & Air Propeller & 100 & & & \\
\hline \multicolumn{6}{|c|}{ Berat total wahana $\Sigma W_{t}=2807 \mathrm{gr}$} \\
\hline
\end{tabular}

3.3 Menentukan Titik Berat Wahana (Center of Gravity)

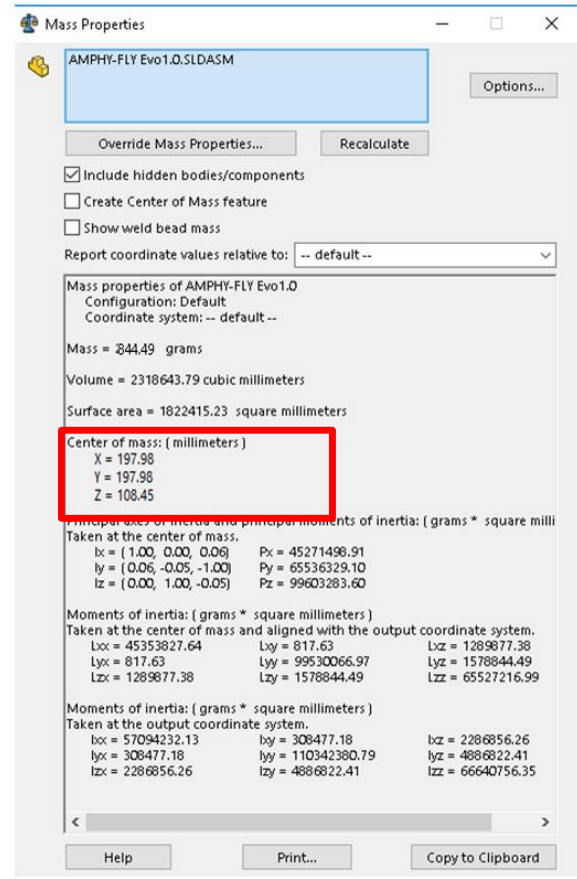

Gambar 3. Hasil Perhitungan Titik Berat Pada Software Solidworks 2018 
Agung Dwi Sapto dkk /Jurnal Rekayasa Mesin

p-ISSN: 1411-6863, e-ISSN: 2540-7678

Vol.16|No.2|148-156|Agustus|2021

Titik berat atau center of gravity adalah titik penting dalam perancangan wahana UAV. Berfungsi sebagai titik tumpuan beban dan titik keseimbangan pada wahana sehingga posisi titik center of gravity $(\mathrm{CG})$ akan bepengaruh untuk menentukan posisi komponen pada wahana UAV. Letak titik CG secara 3 dimensi mempunyai titik koordinat berdasarkan 3 garis sumbu yaitu terhadap sumbu X,Y, dan Z. Sehingga titik ini ditentukan dari 2 pandangan yaitu pandangan atas untuk koordinat $\mathrm{X}$ dan $\mathrm{Y}$ dan pandangan samping untuk kordinat $\mathrm{Y}$ dan $\mathrm{Z}$. Penentuan titik CG pada wahana dibantu dengan software perancangan Solidworks 2018 dengan kondisi wahana tanpa muatan.

Dari hasil yang terlihat pada gambar 3 didapat titik koordinat CG yaitu, pada sumbu $X=197,98 \mathrm{~mm}$, pada sumbu $\mathrm{Y}=197,98 \mathrm{~mm}$ dan pada sumbu $\mathrm{Z}=108,45 \mathrm{~mm}$. Letak titik $\mathrm{CG}$ dari pandangan atas $(\mathrm{X}, \mathrm{Y})$ adalah titik perpotongan antara 2 garis diagonal wheel base. Untuk letak titik CG pada pandangan samping (Y,Z) bergantung pada bentuk dan dimensi komponen dengan titik tumpuan, pada wahana UAV bertumpu pada 4 titik dudukan motor udara (wheel base).

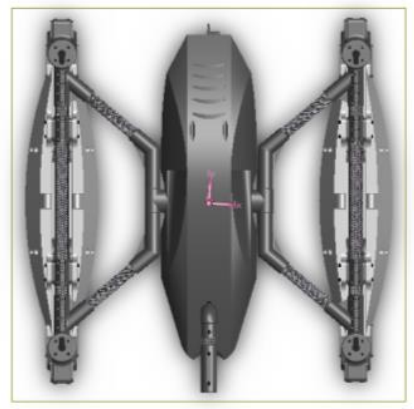

(a)

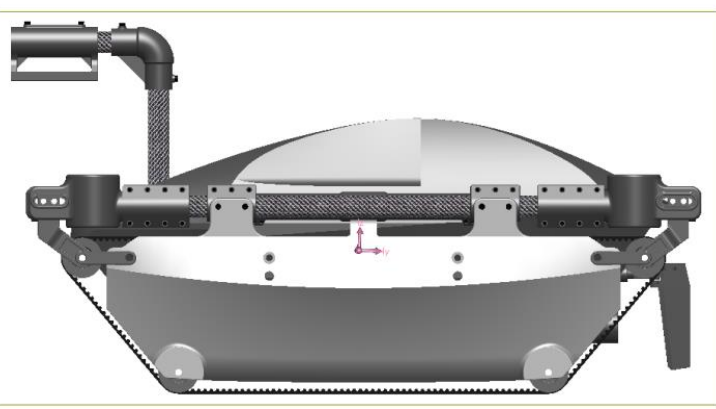

(b)

Gambar 4. Titik Berat Dari (a) Tampak Atas /X,Y dan (b) Tampak Samping/Y,Z

\subsection{Pemilihan Frame}

Pemilihan Frame pada wahana UAV AMPHI-FLY Evo1.0, berdasarkan jumlah dan bobot estimasi komponen pada Tabel 4.1, dan untuk menjalankan misi pencarian dan penyeamatan (SAR), maka ditentukan spesifkasi Frame sebagai berikut:

1. Material yang digunakan pada Frame:

Bahan yang dipilih untuk perancangan Frame pada wahana UAV AMPHI-FLY Evo1.0 adalah material Carbon Fiber untuk bagian Frame arm dan ABS (Acrylonitrile Butadiene Styrene) untuk komponen sambungan dan main bracket.

Tabel 2. Tabel Jenis Material Frame

\begin{tabular}{clccc}
\hline No. & \multicolumn{1}{c}{ Jenis Material } & Modulus Elacticity $(\mathbf{G P a})$ & Tensile Strength (MPa) & Density $\left(\mathbf{K g} / \mathbf{m}^{\mathbf{3}}\right)$ \\
\hline 1. & Carbon Fiber & 35,9 & 103 & 1750 \\
2. & ABS (Acrylonitrile Butadiene & 2,24 & 20 & 1240 \\
& Styrene)
\end{tabular}

\section{Bentuk Frame}

Berdasarkan pertimbangan jumlah komponen, estimasi bobot wahana, stabilitas, dan misi wahana .Bentuk Frame yang digunakan adalah jenis quadcopter Frame yang memiliki 4 dudukan motor penggerak udara, dengan bentuk stretch $X$ Frame, karena memiliki stabilitas cukup baik dan memiliki ruang penyimpanan komponen yang cukup luas, dibandingkan dengan bentuk quadcopter Frame yang lainnya. 
Agung Dwi Sapto dkk /Jurnal Rekayasa Mesin

p-ISSN: 1411-6863, e-ISSN: 2540-7678

Vol.16|No.2|148-156|Agustus|2021

3. Ukuran Frame

Ukuran Frame yang dipilih berdasarkan tabel 2 Adalah Frame dengan jarak diagonal antar wheelbase $560 \mathrm{~mm}$

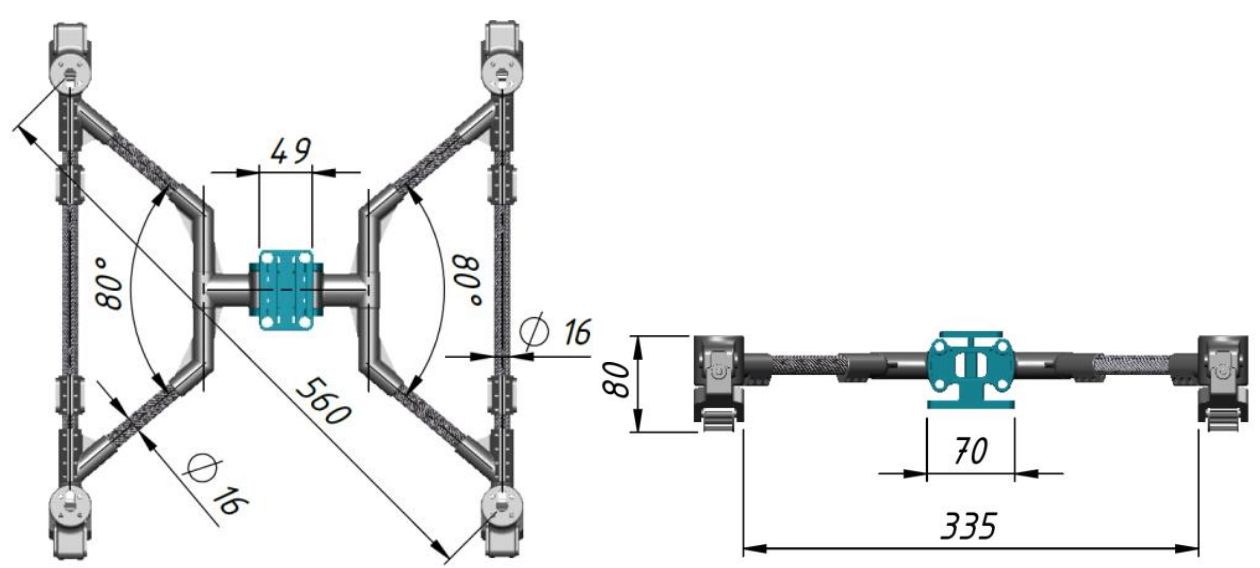

(a)

(b)

Gambar 5. Ukuran Frame (a) Pandangan Atas (b) Pandangan Depan

\subsection{Analisis Body}

Komponen body memiliki pengaruh hambatan yang besar terhadap wahana. Sehingga dalam perancangannya menitikberatkan pada bentuk yang dapat meminimalkan nilai hambatan (coefficient drag) terhadap fluida pada saat wahana bergerak di udara dan di permukaan air. Dalam perancangannya, bentuk rancangan dibuat dengan bentuk streamlined body, kemudian dianalisa dengan metode Computational Fluids Dynamic (CFD) pada software Solidwork 2018. Dengan parameter berdasarkan tabel 3 berikut:

Tabel 3. Flow Simulation Parameter

\begin{tabular}{clc}
\hline No. & \multicolumn{1}{c}{ Parameter } & Keterangan \\
\hline $\mathbf{1 .}$ & Jenis analisa aliran & External flow simulation \\
$\mathbf{2 .}$ & Jenis fluida & Udara \\
$\mathbf{3 .}$ & Massa jenis fluida $(\rho)$ & $1,225 \mathrm{Kg} / \mathrm{m}^{3}$ \\
$\mathbf{4 .}$ & Kecepatan fluida $(v)$ & $10 \mathrm{~m} / \mathrm{s}$ \\
$\mathbf{5}$ & Tekanan fluida $(P)$ & $101325 \mathrm{~Pa}$ \\
$\mathbf{6}$ & Suhu fluida $\left(T_{f}\right)$ & $20,05^{\circ} \mathrm{C}$ \\
$\mathbf{7}$ & Luas permukaan $\operatorname{body}(A)$ & $0,195 \mathrm{~m}^{2}$ \\
\hline
\end{tabular}

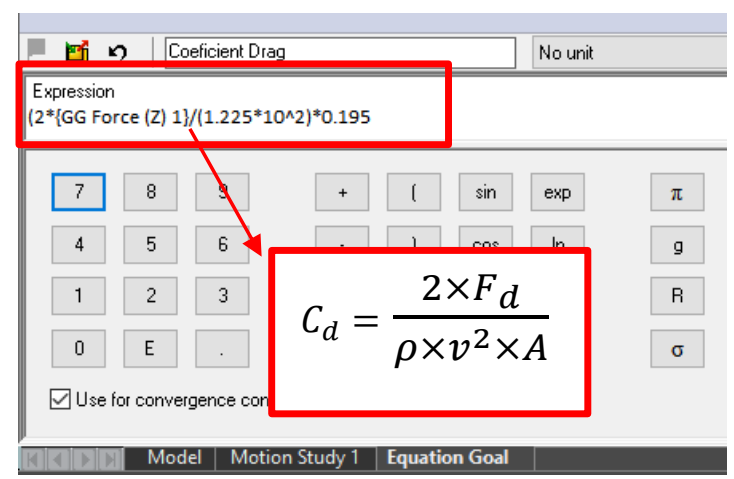

Gambar 6. Memasukan Persamaan Coeficient Drag 
Agung Dwi Sapto dkk /Jurnal Rekayasa Mesin

p-ISSN: 1411-6863, e-ISSN: 2540-7678

Vol.16|No.2|148-156|Agustus|2021

Hasil dari proses perhitungan dapat ditampilkan dengan visualisasi berdasarkan warna dan besar nilai dari masingmasing goals dengan menggunakan fungsi "cut plots". Seperti pada gambar 7 ditunjukan nilai velocity fluida disekitar body dengan nilai minimum $0 \mathrm{~m} / \mathrm{s}$ hingga maksimum $10,858 \mathrm{~m} / \mathrm{s}$.

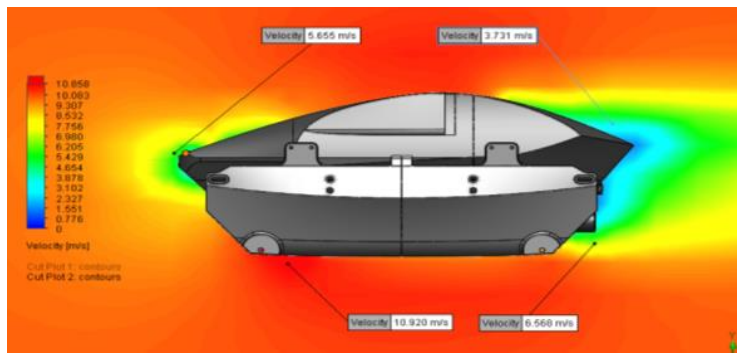

(a)

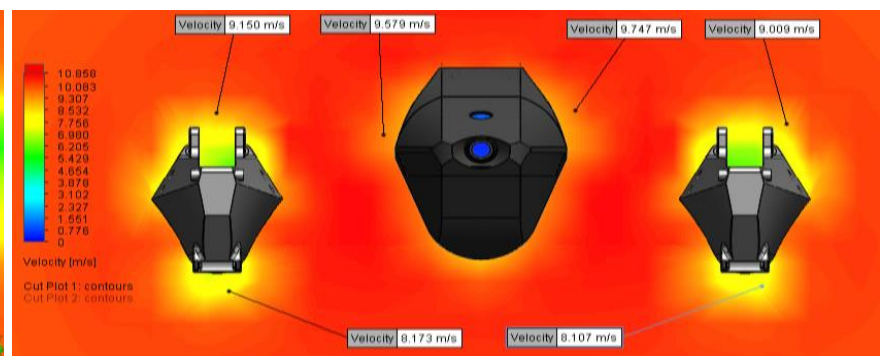

(b)

Gambar 7. Hasil Analisis Untuk Velocity Fluida (a) Tampak Samping (b) Tampak Depan

Kemudian pada gambar 8 dapat dilihat menunjukan hasil analisis $C F D$ untuk nilai tekanan fluida yang bekerja pada body wahana AMPHI-FLY Evo 1.0, dengan nilai dari101278.95Pa hingga 101511,37Pa. Dan pada gambar 9 menunjukan hasil analisis untuk densitas fluida di sekitar body dengan nilai $1,20 \mathrm{Kg} / \mathrm{m}^{3}$ hingga $1,21 \mathrm{Kg} / \mathrm{m}^{3}$.

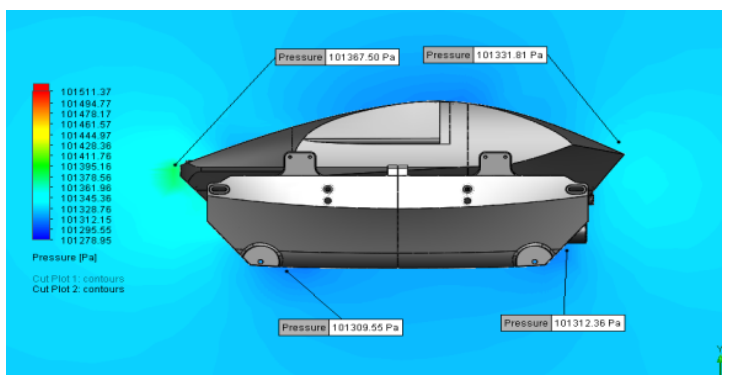

(a)

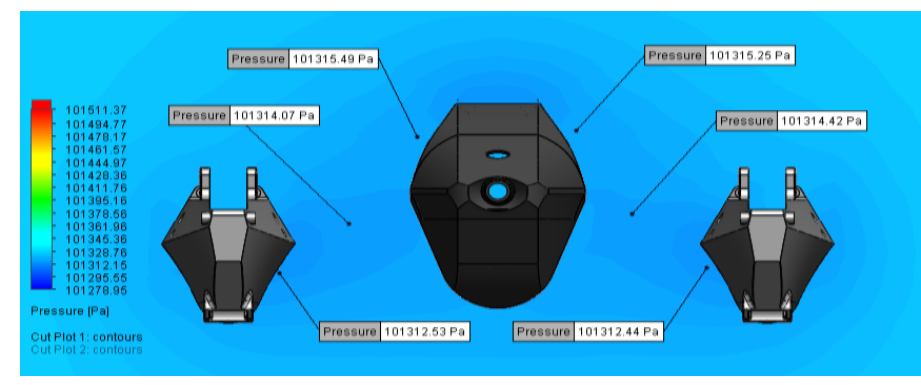

(b)

Gambar 8. Hasil Analisis Untuk Pressure Fluida (a) Tampak Samping (b) Tampak Depan

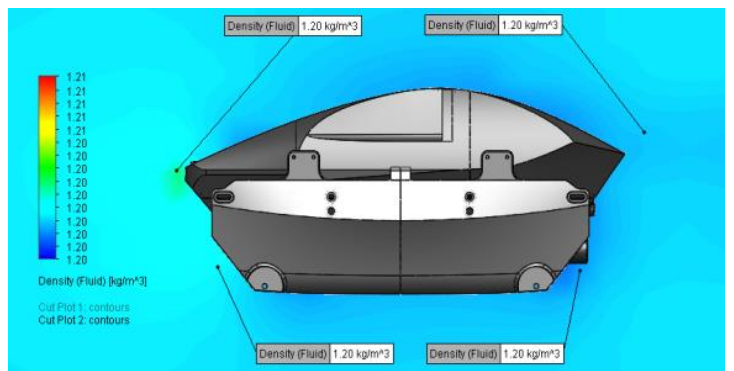

(a)

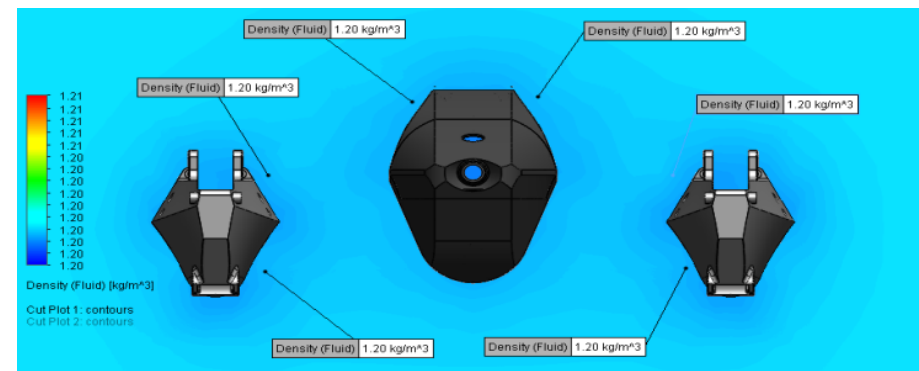

(b)

Gambar 9. Hasil Analisis Untuk Density Fluida (a) Tampak Samping (b) Tampak Depan

Dari hasil simulasi dapat dilihat nilai coefficient drag pada body seperti pada grafik gambar 10 dapat diketahui $C_{d}$ ${ }_{(\text {minimum })}=0,0195701$

$C_{d \text { (maksimum })}=0,0201424 C_{d \text { (average })}=0,0198562 \approx 0,0$ (Memenuhi syarat $\left.\leq 0,04\right)$. Sedangkan daya hambatan pada body $\left(P_{d}\right)$ menggunakan data nilai $v$ dan $A$ dari tabel 3 , dan nilai $C d$ maksimum sehingga didapatkan sebesar 2,4058 watt. 


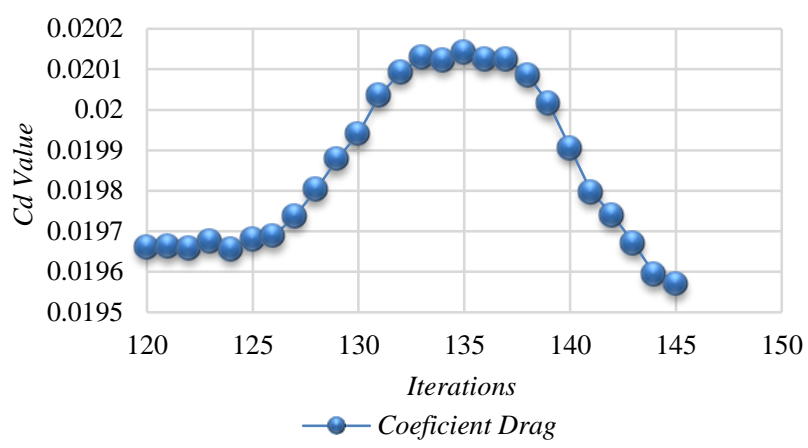

Gambar 10. Grafik Coeficient Drag Body Wahana

\section{Kesimpulan}

Hasil perancangan wahana Unmanned Aerial Vehicle (UAV) AMPHI-FLY Evo 1.0 dapat disimpulkan berdasarkan hasil penimbangan, dan fungsi mass properties dari software Solidworks 2018 didapat bobot total wahana, sebesar: $\Sigma W_{t}=2807 \mathrm{gr} \approx 2,8 \mathrm{Kg}$. Titik berat Wahana dari hasil analisa pada software Solidworks 2018, diketahui berada pada koordinat X (197,98mm), Y (197,98mm) dan Z (108,45mm). Berdasarkan perancangan Frame, dipilih material yang digunakan untuk membentuk Frame, untuk bagian arms menggunkan material tipe carbon fiber tube, untuk bagian komponen sambungan, main bracket, dan dudukan motor menggunakan material tipe ABS. Dengan bentuk Frame tipe stretch X-Frame, dan ukuran jarak antar wheelbase $560 \mathrm{~mm}$. Berdasarkan dari hasil perancangan body dibuat bentuk yang streamlined seperti pada lampiran. Dengan hasil dari metode Computational Fluids Dynamic (CFD) pada software Solidwork 2018 di dapat nilai coefficient drag (rata-rata), $C_{d(\text { (average })}=0,0198562$ dan daya hambatan, $P_{d}=$ 2,4058 watt.

\section{Daftar Pustaka}

[1] https://www.cnbcindonesia.com/news/20181231171146-4-48559/bnpb-ri-ditimpa-2564-bencana-dan-merugi-rp100-t-di-2018, (Diakses pada hari Jumat, Tanggal 3 Januari 2019, Jam 10.28 WIB.)

[2] https://regional.kompas.com/read/2019/01/24/15340291/keluarga-sudah-ikhlas-pencarian-alvi-di-gunung-lawudihentikan, (Diakses pada hari Jumat, Tanggal 25 Januari 2019, Jam 10.30 WIB)

[3] Dhiky Hartono, Soni Darmawan. Pemanfaatan Unmanned Aerial Vehicle (UAV) Jenis Quadcopter untuk Percepatan Pemetaan Bidang Tanah (Studi Kasus: Desa Solokan Jeruk Kabupaten Bandung) Reka Geomatika , Jurnal Online Institut Teknologi Nasional, No.1 | Vol. 2018 | 30-40

[4] Alivza Sontonojaya. Rancang Bangun Kapal Tanpa Awak Untuk Mengukur Magnitudo Pinger Dengan Hydrophone Sensor. Departemen Teknik Elektro Otomasi, Fakultas Vokasi, Institut Teknologi Sepuluh Nopember, Surabaya 2018.

[5] Naufal Arif Prasetyo, Dr. Eng, Herianto, S.T., M.Eng. Perancangan Kendaraan Tanpa Awak (Unmanned Ground Vehicle) Untuk Misi Pemantauan Bencana. Skripsi, S1 Teknik Mesin, Universitas Gadjah Mada, Yogyakarta, 2016.

[6] Whitmore, Maj Bishane A., Evolution of Unmanned Aerial Warfare: A Historical Look At Remote Airpower. Thesis, Kansas (2016): United States Army Command and General Staff Collage.

[7] Valavanis, Kimon P. and George J.V. Handbook of Unmanned Aerial Vehicles. New York (2015): SpringerReference. 
[8] Balachandran, Akshay, et al. Material Selection for Unmanned Aerial Vehicle. International Journal of Mechanical Engineering \& Technology (IJMET) (2014), No.5. 34-40.

[9] Baichtal, John. Building Your Own Drones: A Beginners Guide to Drones, UAVs, and ROVs. Indiana (2016): QuePublishing.

[10] Bone, Elizabeth. and Christopher Bolkcom. Unmanned Aerial Vehicle: Background and Issues for Congress. Washington DC (2003): The Library of Congress.

[11] Hoang, Michael. and Tik W.K. Poon. Final Report: Design, Implementation, and Testing of An UAV Quadcopter. Winnipeg (2013): University of Manitoba.

[12] Houghton, W.L., et al. Aerodynamic for Engineering Students. 6th Edition, London (2013): ButterworthHeinemann.

[13] Kenneth S.H. Prinsip-prinsip Perancangan Teknik. Jakarta (2006): Penerbit Erlangga.

[14] Pahl, G. and W Beitz., Engineering Design: A Systematic Approach. 3rd Edition. London (2007): Springer-Verlag

[15] https://discuss.ardupilot.org/t/building-a-better-quad-Frame/27703/7, (Diakses pada hari Minggu, Tanggal 18 November 2018, Jam 14.22 WIB) 